\title{
Comparative Analysis of Routing Internet Protocol and Open Shortest Path First Protocols Using QUALNET
}

\author{
A. S. Alatishe, A. A. Atayero, O. I. Oshin
}

\begin{abstract}
Reliability is a major consideration in Network Design and Implementation in order to cater for link failures. Link failure is a frequent occurrence in Networks and Communications Systems, and the speed at which this disruption is noticed and (or) fixed varies. The use of dynamic routing means in case of link failure, the routers are able to learn alternate routes via periodic updates about the network topology and link states from its neighbors. This report shows how to simulate and study how dynamic routing protocols such Link state and Distance-vector routing protocols respond to link failures and restart, their performance is compared using Qualnet.
\end{abstract}

Keywords-LTE, Scheduling, Throughput, 3GPP

\section{Introduction}

Communications has become almost as important as the air we breathe in recent times, and this is evident in the rapid growth of communications that includes services such as texting, file sharing, video streaming and conference calls; these services have been aided by advancements in technologies providing the network infrastructure.

Network Communications uses digital techniques such as routing and switching of data. Routing is a process that occurs at the Internet/Network layer and it is not based on the destination address only; it considers the topology and prevailing traffic conditions. The process by which a router sends packets from a source to the destination is termed routing [8].

Interconnected routers do not learn the network in isolation; they exchange information and updates about the network using routing protocols. The learnt network topology is used to build maps referred to as routing-tables that contain the best routes to destinations.

Routing protocols describe how routers share information across a network [4], without them this won't be possible. Routing protocols are important as it provides routers with information necessary to send packets correctly. These routing protocols are usually based on an algorithm that defines the processes needed to make the protocol work correctly. These processes include:

- The process for sending and receiving network information.

- The process for finding the best path to a destination and installing it into the routing table.

- The process to detect, adjust and inform other routers about network topology changes.

Department of Electrical and Information Engineering

Covenant University, Nigeria

\section{A. Routing Protocols}

These have been classified into several groups using their characteristics such as Interior Gateway Routing Protocols (IGRP) and Exterior Gateway Routing Protocol (EGRP), Dynamic Routing Protocols, Distance Vector and Link State Routing Protocol [7]. A routing protocol is considered dynamic if it follows the rules defined in its algorithm for exchanging routing information and selecting the best path at run time, they require less administrative overhead and one of its disadvantages is routing loops [9]. A routing protocol is classified as a distance vector routing protocol if its operation is centered on distance (Number of routers) and direction to the recipient such as Routing Internet Protocol (RIP). Link State routing Protocols determine the best path to the destination based on least cost such as Open Shortest Part First (OSPF). Cost doesn't imply monetary considerations; it denotes parameters of importance to the network operator (called metrics) such as bandwidth, load, delay, reliability and hop count [3].

\section{B. Routing Internet Protocol (RIP)}

This is defined by RFC 1058, and 1723 is based on the Bellman, Ford and Fulkerson Algorithm. It uses hop count; number of routers the data will traverse before reaching the destination. It is a distance vector protocol and doesn't consider bandwidth or delay in its routing decision. RIP requires substantial overhead because it transmits the entire routing table every time it updates. It is suitable for small networks only because of its slow convergence, which could cause routing loops. Two ways the problem of routing loops in RIP can be resolved are by specifying the maximum number of hops as fifteen and split horizon [1].

\section{Open Shortest Path First (OSPF)}

This is described in RFC 1131, 2178. It runs on Djikistra's Algorithm. This is a link state protocol and is preferred for medium to large networks. OSPF specifies the shortest path based on cost. OSPF demands more processing and memory requirement than RIP, and it consumes a large bandwidth at the initial link-state packet flooding. OSPF is not as bandwidth intensive as RIP this is because it advertises only the changes in the state of its routing tables to other routers using link state advertisements (LSA) rather than full routing tables.

\section{Design and Simulation}

The simulation design simulates a real life design with access routers (nodes 1, 2, 7 and 8) and distribution routers 
(3, 4, 5, and 6). There is a sending node (node 9) and a receiving node (node 10). There are ten (nodes) in all.

There are thirteen links, with links between nodes $1 \& 3$, $3 \& 4,3 \& 5,5 \& 7$ and $7 \& 8$ set to 1 Gbps while links between nodes $1 \& 2,2 \& 4,4 \& 6,5 \& 6,6 \& 8$, and $3 \& 6$ set to $100 \mathrm{Mbps}$. The connections between the nodes $9 \& 10$ with the access routers is wireless at $10 \mathrm{Mbps}$. From literature OSPF is said to choose the path with the least cost (higher bandwidth), this why some links are set to a higher bandwidth to also investigate the phenomena.

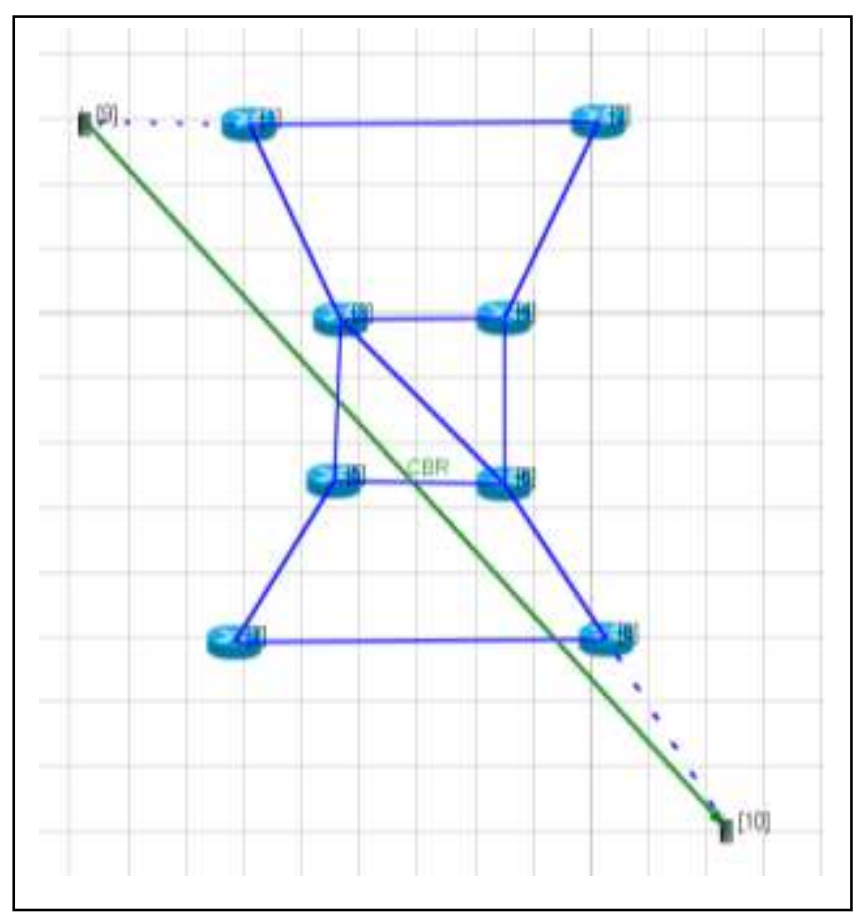

Figure 1. Network Architecture of the Simulation

\section{A. Definition of Collected Statistics}

Convergence: This is a state whereby routers in a network possess the same topological details about the internetwork in which they operate that is all routers agree on the topology of the network.

Convergence time: This is defined the time it takes all routers on a network to reach a state of convergence. The larger the network the slower convergence takes place [2].

End-to-End Delay: This is the time it takes a packet to travel to the destination after it was generated at the source [6]. This is the total sum of all delays from start of transmission to the finish.

Packet Delivery: The ratio of the number of packets delivered to the receiver to the number of packets sent by the transmitter [5].

Throughput: This is the rate (usually in bits per sec) at which bits are transferred between and receiver.

\section{B. Scenario 1 without faults}

This scenario is run without any link failure. The shortest path between the client (9) and server (10) is the link from router 1 to router 3 to router 6 to router 8 .
TABLE I - SCENARIO 1 WITH NOFAULTS

\begin{tabular}{|c|c|c|}
\hline Parameters & RIPv2 & OSPFv2 \\
\hline Simulation time & \multicolumn{2}{|c|}{100 seconds } \\
\hline Application between hosts & \multicolumn{2}{|c|}{ CBR } \\
\hline Convergence time & 13 seconds & 16 seconds \\
\hline $\begin{array}{c}\text { Client's Total Unicast Data } \\
\text { Sent (Bytes) }\end{array}$ & 50688 & 50688 \\
\hline $\begin{array}{l}\text { Server's Total Unicast Data } \\
\text { Received (Bytes) }\end{array}$ & 44544 & 43008 \\
\hline Packet Delivery & $87.88 \%$ & $84.85 \%$ \\
\hline $\begin{array}{l}\text { Server's Unicast Received } \\
\text { Throughput (bps) }\end{array}$ & 4143.63 & 4145.35 \\
\hline $\begin{array}{l}\text { Average Unicast End-to-End } \\
\text { Delay }(\mathrm{Sec})\end{array}$ & 0.004457 & 0.004007 \\
\hline
\end{tabular}

It is evident that for a small network with no faults RIPv2 performs better, this is seen in the throughput of network when simulated using RIP and OSPF. Also RIP converges faster under this situation and has a higher packet delivery when compared to OSPF. Although it was noticed that OSPF nodes had better average delay at each nodes compared to RIP nodes.

\section{Scenario 2 with a single fault}

The scenario uses the same topology as the first scenario but a link failure was inserted between router 1 and router 3 (The shortest path) from the $40^{\text {th }}$ to the $70^{\text {th }}$ second. All speeds remain constant.

TABLE II. SCENARIO 2 WITH WITH A SINGLE FAULT

\begin{tabular}{|l|l|l|}
\hline \multicolumn{1}{|c|}{ Parameters } & RIPv2 & OSPFv2 \\
\hline \multicolumn{1}{|c|}{ Simulation time } & \multicolumn{2}{|c|}{100 seconds } \\
\hline Application between hosts & \multicolumn{2}{|c|}{ CBR } \\
\hline \multicolumn{1}{|c|}{ Number of Routers } & 13 seconds & 16 seconds \\
\hline Convergence time before faults & 6 seconds \\
\hline $\begin{array}{l}\text { Convergence time after fault } \\
\text { occurred }\end{array}$ & 23 seconds & 12 seconds \\
\hline $\begin{array}{l}\text { Convergence time after fault } \\
\text { was resolved }\end{array}$ & 23 seconds \\
\hline $\begin{array}{l}\text { Client's Total Unicast Data } \\
\text { Sent (Bytes) }\end{array}$ & 50688 & 50688 \\
\hline $\begin{array}{l}\text { Server's Total Unicast Data } \\
\text { Received (Bytes) }\end{array}$ & 32768 & 42496 \\
\hline \multicolumn{1}{|c|}{ Packet Delivery } & $64.65 \%$ & $83.84 \%$ \\
\hline $\begin{array}{l}\text { Server's Unicast Received } \\
\text { Throughput (bps) }\end{array}$ & 3048.19 & 4096 \\
\hline $\begin{array}{l}\text { Average Unicast End-to-End } \\
\text { Delay (Sec) }\end{array}$ & 0.004696 & 0.004531 \\
\hline
\end{tabular}

It is evident that the packet delivery and throughput for nodes using OSPF is considerably higher with a fault introduced in scenario 2 than with RIPv2 as shown in the table above. Also it is shown that OSPF converges faster after a fault occurs. This is a desirable quality in network design and implementation. 


\section{Scenario 3 with a single fault at the beginning of the simulation}

The scenario uses the same topology as the first scenario but a link failure was inserted between router 1 and router 3 (The shortest path) from the $5^{\text {th }}$ to the $40^{\text {th }}$ second. All speeds remain constant. This to investigate how RIP and OSPF handles link fault that occur before it updates its routing table.

TABLE III. STATISTICS FROM SINGLE FAULT SIMULATION STARTING AT $5 \mathrm{~s}$

\begin{tabular}{|l|l|l|}
\hline \multicolumn{1}{|c|}{ Parameters } & RIPv2 & OSPFv2 \\
\hline \multicolumn{1}{|c|}{ Simulation time } & \multicolumn{2}{|c|}{100 seconds } \\
\hline Application between hosts & \multicolumn{2}{|c|}{ CBR } \\
\hline Number of Routers & \multicolumn{2}{|c|}{8} \\
\hline $\begin{array}{l}\text { Convergence time after } \\
\text { fault occurred }\end{array}$ & 15 seconds & 21 seconds \\
\hline $\begin{array}{l}\text { Convergence time after } \\
\text { fault was resolved }\end{array}$ & 23 seconds & 10 seconds \\
\hline $\begin{array}{l}\text { Client's Total Unicast } \\
\text { Data Sent (Bytes) }\end{array}$ & 50688 & 50688 \\
\hline $\begin{array}{l}\text { Server's Total Unicast } \\
\text { Data Received (Bytes) }\end{array}$ & 43520 & 40448 \\
\hline \multicolumn{1}{|c|}{ Packet Delivery } & $85.86 \%$ & $79.80 \%$ \\
\hline $\begin{array}{l}\text { Server's Unicast Received } \\
\text { Throughput (bps) }\end{array}$ & 4144.79 & 4148.57 \\
\hline $\begin{array}{l}\text { Average Unicast End-to- } \\
\text { End Delay (Sec) }\end{array}$ & 0.004787 & 0.004351 \\
\hline
\end{tabular}

In this simulation RIP has a better packet delivery statistic but OSPF has a better End-to-End delay and Converges faster after fault was resolved. RIP converges faster initially because OSPF has to map out the entire network before transmitting.

\section{E. Scenario 4 with multiple faults}

The scenario uses the same topology as the first scenario but link failures were inserted between router 1 and router 3 (The shortest path) from the $20^{\text {th }}$ to the $40^{\text {th }}$ second and between router 4 and router 6 from the $50^{\text {th }}$ to the $80^{\text {th }}$ second. All speeds remain constant.

TABLE IV. STATISTICS FROM MULTIPLE FAULTS SCENARIO SIMULATION

\begin{tabular}{|l|l|l|}
\hline \multicolumn{1}{|c|}{ Parameters } & RIPv2 & OSPFv2 \\
\hline Simulation time & \multicolumn{2}{|c|}{ 100 seconds } \\
\hline Application between hosts & \multicolumn{2}{|c|}{ CBR } \\
\hline Number of Routers & \multicolumn{2}{|c|}{8} \\
\hline \multicolumn{1}{|c|}{ Convergence time } & 13 seconds & 16 seconds \\
\hline $\begin{array}{l}\text { Convergence time after } \\
\text { first fault }\end{array}$ & 14 seconds & 4 seconds \\
\hline $\begin{array}{l}\text { Convergence time after } \\
\text { Second fault }\end{array}$ & 10 seconds & 4 seconds \\
\hline $\begin{array}{l}\text { Client's Total Unicast } \\
\text { Data Sent (Bytes) }\end{array}$ & 50688 & 50688 \\
\hline
\end{tabular}

\begin{tabular}{|l|l|l|}
\hline $\begin{array}{l}\text { Server's Total Unicast } \\
\text { Data Received (Bytes) }\end{array}$ & 34304 & 41984 \\
\hline Packet Delivery & $67.68 \%$ & $82.83 \%$ \\
\hline $\begin{array}{l}\text { Server's Unicast Received } \\
\text { Throughput (bps) }\end{array}$ & 3191.07 & 4046.65 \\
\hline $\begin{array}{l}\text { Average Unicast End-to- } \\
\text { End Delay (Sec) }\end{array}$ & 0.004619 & 0.004392 \\
\hline
\end{tabular}

\section{Results and Analysis}

In the above simulations when RIP was used as the routing protocol, It is evident that shortest path is via routers 1 to 3 to 6 to 8 . It was observed that the average delay at each node using RIP was smallest when no fault occurred and highest when the fault occurs before convergence as carried out in scenario 3 . This is to be expected due to the sudden change in the network topology before convergence.

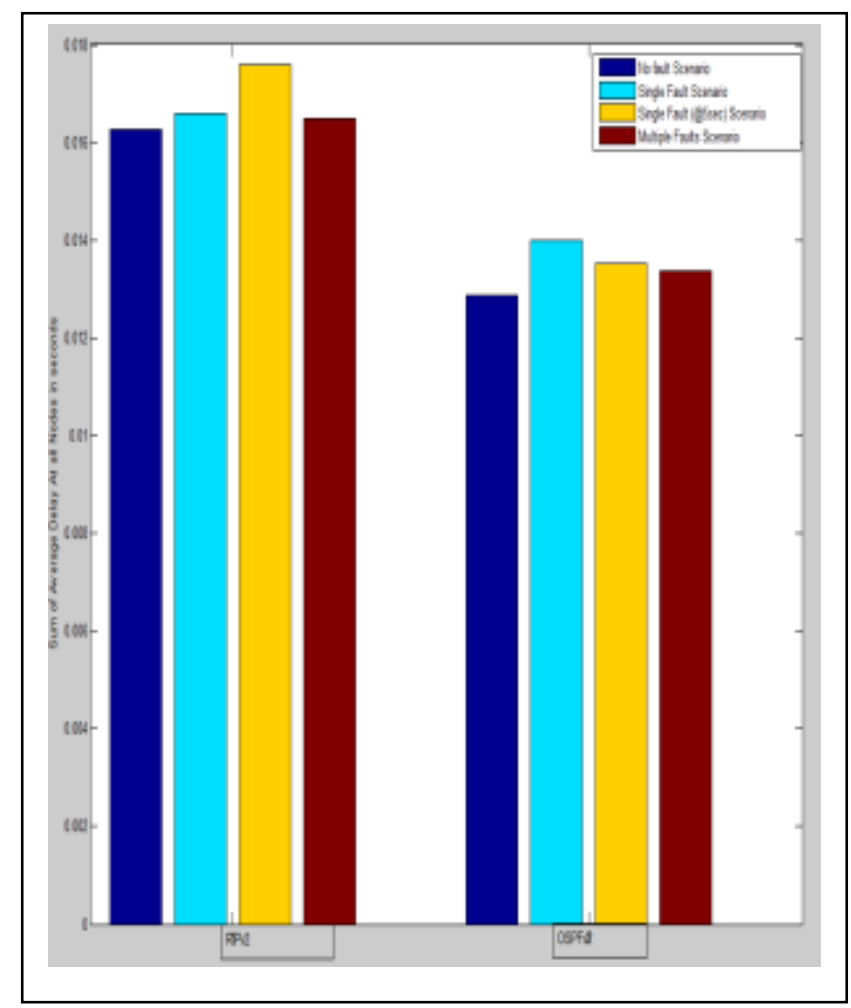

Figure 2. Total average delay at nodes using RIP and OSPF

Overall OSPF has a better average delay at all nodes under all scenarios. This is shown in Figure 2 above. 


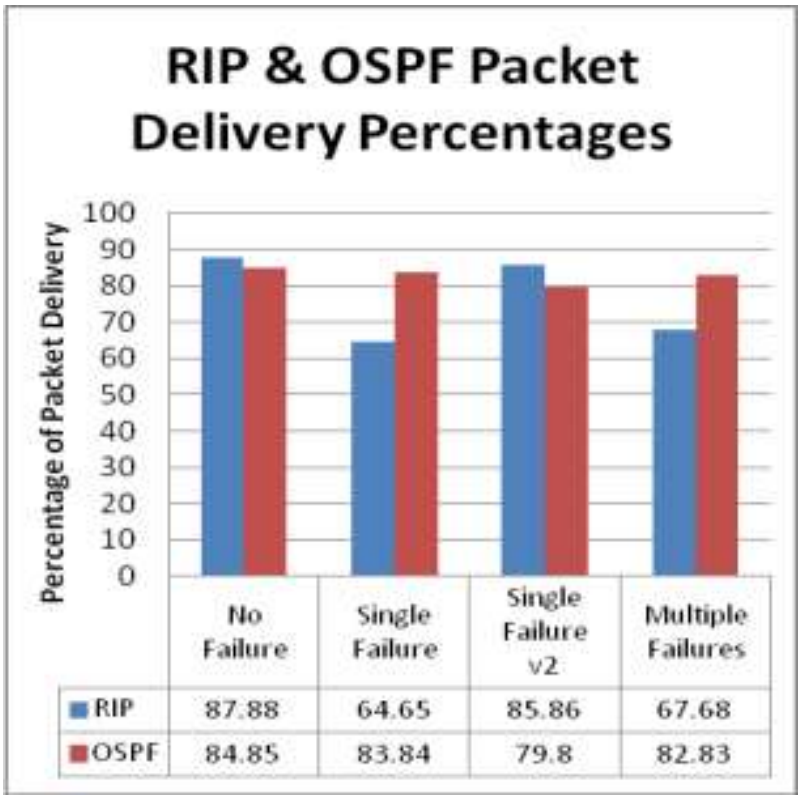

Figure 3. Packet delivery percentage

The chart above (Plotted using Ms Excel) shows that on average OSPF has better packet delivery with link failure this is due to its fast convergence times after link failures.

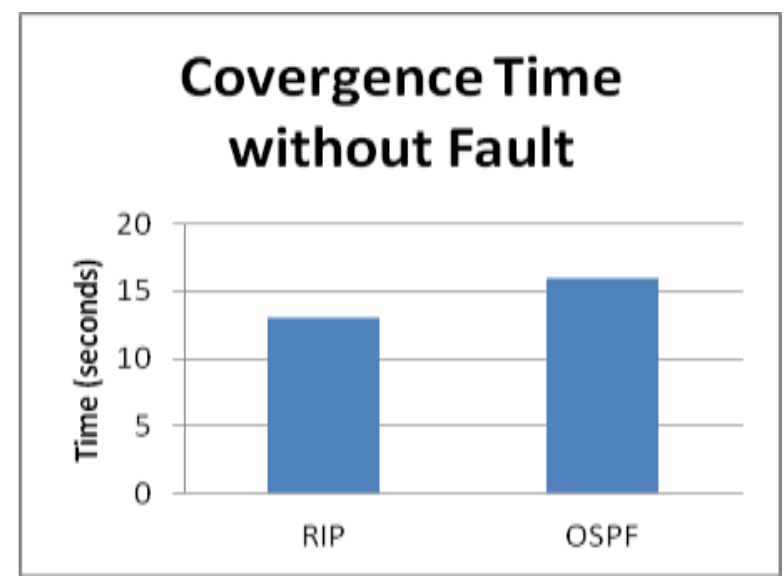

Figure 4. Convergence Time for Scenario 1

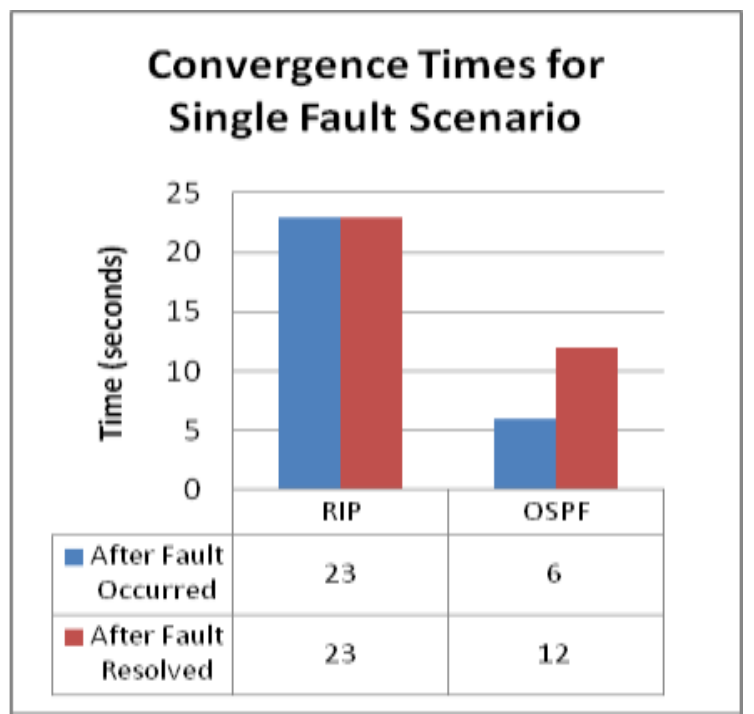

Figure 5. Convergence Time for Scenario 2

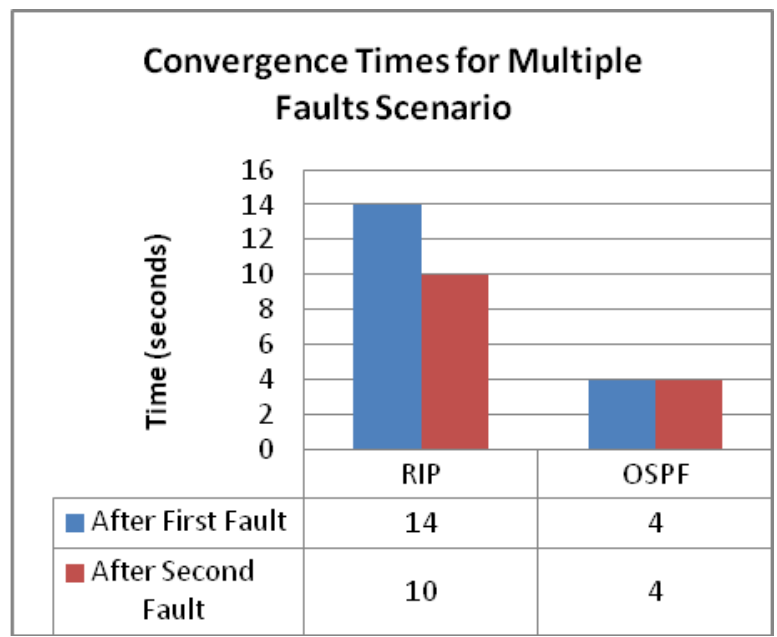

Figure 6. Convergence Time for Scenario 4

\section{Iv. Evaluations and Conclusion}

In this Simulation work, RIP initially converges faster OSPF, but OSPF has shown better convergence times after link failures and link restart as shown in tables 1 to 4 . For RIP, when the network fails it takes longer to transfer this information to all routers whereas OSPF supports multiple routes for a single destination in the network.

The Simulation results show that the average end-to-end delay in OSPF networks is relatively lower than those of RIP networks.

Percentage of Packet delivered was compared; OSPF outperforms RIP when link failure occurs. When there is no link failure the two protocols performance is close.

\section{References}

[1] Cisco Systems, "Introduction to Cisco Router Configuration," Cisco Press, 1998.

[2] Cockcroft, L., "Understanding the protocols underlying dynamic routing," From TechRepublic: http://www.techrepublic.com/article/ understanding-the-protocols-underlying-dynamic-routing/, May 2010.

[3] R. A. Graziani, "Routing Protocols and Concepts," CCNA Exploration Companion Guide, Cisco Press, 2008, pp. 148 - 179.

[4] Islam, M. N., "Simulation Based EIGRP over OSPF," Master Thesis in Electrical Engineering Emphasis on Telecommunications, Sweden: Blekinge Institute of Technology, 2010.

[5] Harrismare, "Packet Delivery Ratio, Packet Lost, End To End Delay," From HARRISMARE: http://harrismare.net/2011/07/14/packetdelivery-ratio-packet-lost-end-to-end-delay/, May 2011.

[6] Jia Liu, X. J., "End-to-End Delay in Mobile Ad Hoc Networks with Generalized Transmission Range and Limited Packet Redundancy," IEEE Wireless Communications and Networking Conference, Paris 2012, pp. 1731-1736.

[7] Lancaster, D. S., "Routing Protocol Convergence Comparison," Advances in Communications, Computing, Networks and Security, 2010, pp. 186 - 194

[8] Michael Duck, R. R., "Data Communications and Computer Networks for Computer Scientists and Engineers," 2nd Edition. Prentice Hall, 2003.

[9] Shah A., W. J., "Performance Analysis of RIP and OSPF in Network," International Journal of Computer Science Issues, Vol. 10, Issue 6, No. 2, 2013, pp. 256 - 265 